\section{Antimicrobial Behavior of Zinc Oxide Nanoparticles and $\beta$-Lactam Antibiotics against Pathogenic Bacteria}

\section{Abstract}

Background: Multi-drug resistance among the pathogenic bacteria poses a serious threat to public health. Nanoparticles are one of the most effective therapeutic agents. Zinc oxide nanoparticles (ZnO NPs) are well known antimicrobial agents and are regarded as nontoxic and bio-safe. The present study aims to investigate the antimicrobial effect of ZnO NPs against the bacterial strains i.e. Klebsiella pneumoniae (K. pneumoniae) and Escherichia coli (E.coli).

Methodology: The antibacterial activity was performed by Kirby's Disc diffusion assay using different concentrations $(0.2,0.4,0.6,0.8$ and 1.0$) \mathrm{mg} / \mathrm{ml}$ of $\mathrm{ZnO} \mathrm{NPs}$ with and without $\beta$ lactam antibiotics (Ciprofloxacin and Imipenem). The Minimum inhibitory concentration (MIC) was evaluated through the standard agar dilution method. Antioxidant potential of ZnO NPs was analyzed through $\alpha \alpha$-diphenyl- $\beta$ picrylhydrazyl (DPPH) radical scavenging activity while the Cytotoxicity of ZnO NPs was evaluated through Brine shrimp lethality assay.

Results: The results revealed that the highest zone of inhibition was more in $K$. pneumoniae i.e. $27.2 \mathrm{~mm}$ as compared to E.coli i.e. $13.2 \mathrm{~mm}$. The MIC value for $K$. pneumoniae and E.coli was $0.05 \mathrm{mg} / \mathrm{ml}$ and $0.08 \mathrm{mg} / \mathrm{ml}$ respectively. Antioxidant potential of $\mathrm{ZnO}$ NPs increases as the concentration of NPs was increased. However, the cytotoxicity analysis showed the non-toxic effect of ZnO NPs.

Conclusion: The results indicated that ZnO NPs possess strong antimicrobial activity and can enhance the antimicrobial activity of some beta-lactam antibiotics. The present study can be helpful to formulate nano-drug conjugates as antimicrobial agents in various fields of medical and pharmaceutical research.

Keywords: Zinc oxide nanoparticles; Antibacterial; Antibiotics; Antioxidant

\section{Farzana $R^{*}$, Iqra $P$, Shafaq $F$, Sumaira S, Zakia K, Hunaiza T and Husna M}

Lahore College for Women University, Lahore, Punjab Pakistan

*Corresponding author: Farzana R

” dr.farzanarashid@gmail.com

Lahore College for Women University, Jail road Lahore, Lahore, Punjab 54700, Pakistan.

Tel: 923077777730

Citation: Farzana R, Iqra P, Shafaq F, Sumaira S, Zakia K, et al. (2017) Antimicrobial Behavior of Zinc Oxide Nanoparticles and $\beta$-Lactam Antibiotics against Pathogenic Bacteria. Arch Clin Microbiol. Vol. 8 No. 4:57

Received: August 01, 2017; Accepted: August 05, 2017; Published: August 12, 2017

\section{Introduction}

Infectious diseases, whether they are intracellular or extracellular, have always been a global problem to public health, causing millions of deaths each year. The discovery of miracle drugs, called antibiotics in the 20th century resulted in sudden reduction of mortality rate and illness [1]. Currently, over $70 \%$ of bacterial nosocomial infections in the United States are resistant to one or more of the antibiotics use for the treatment [2]. Resistances in these organisms are mainly caused by enzymes called $\beta$-lactamases (beta lactamases) which open $\beta$-lactam ring of penicillin's and cephalosporin's thereby destroying their antibacterial properties. Plasmid encoded $\beta$-lactamases which are capable of hydrolyzing broader spectrum of $\beta$-lactam antibiotics than simple parent $\beta$-lactamases are known as extended spectrum $\beta$-lactamases, they can inactivate $\beta$-lactam antibiotics containing oxyimino group, such as oxyimino-cephalosporins like Cefotaxime etc and oxyimino-monobactams like Aztreonam $[3,4]$.

There are number of physical methods that can eliminate or kill bacteria and other microorganisms from every environment like steam, dry heat or radiation and many chemical methods. But these methods are time and energy consuming and can cause many side effects too [5]. By the chemical modification of existing drugs and discovery of new antibiotics, bacterial 
resistance to antibiotics can be resolved. There is an acute need for more effective and long term solutions to this problem [6]. With the increase in health awareness, many people focused on educating and protecting themselves against harmful pathogens. Nanotechnology has arisen over the past decades. Inorganic materials like metal and metal oxides have ability to withstand harsh processes conditions [7,8]. Nanoparticles have emerged as novel antimicrobial agents owing to their effectiveness in small doses, minimal toxicity and lack of side effects [9]. ZnO NPs are one of the multifunctional inorganic nanoparticles that have many features like chemical and physical stability, effective antibacterial activity as well as intensive ultraviolet and infrared adsorption with broad range of applications [10,11]. ZnO NPs are known to have strong inhibitory and antibacterial effects [12]. Bactericidal activity of such nanoparticles depends upon: 1) Size, 2) Stability and 3) Concentration in the growth medium [13]. The antimicrobial mechanism of ZnO NPs illustrated the direct contact of ZnO-NPs with cell walls, results in destruction of bacterial cell integrity with the liberation of antimicrobial ions mainly $\mathrm{Zn}^{+2}$ ions. Several mechanisms of antibacterial activity of ZnO NPs have been proposed including: (i) the induction of reactive oxygen species including hydrogen peroxide $\left(\mathrm{H}_{2} \mathrm{O}_{2}\right)$, (ii) the damage on cell membrane and interaction of intracellular contents with ZnO NPs. In general, bacterial cellular membranes have pores in nanometer so ZnO NPs have a unique ability of crossing the cell membrane through these pores [14].

Therefore the present study aims to investigate the cytotoxicity, antioxidant and antimicrobial effect of ZnO NPs with $\beta$-lactam antibiotics against pathogenic bacteria.

\section{Materials and Methods}

\section{Bacterial strains and chemicals}

Total twenty bacterial strains from the clinical isolates were collected from the Post Graduate Medical

Institute (PGMI). All Bacterial strains were identified on the basis of biochemical identification and differentiation tests. Out of which, 2 beta lactamases producing strains were selected i.e. Escherichia coli and Klebsiella pneumoniae. They were Imipenem sensitive and Ciprofloxacin resistant.

The ZnO NPs purchased from U.S Research Nanomaterials, Inc. were dissolved in autoclaved distilled water. All the concentrations were vigorously vortexed before performing the experiment.

\section{Antibacterial susceptibility assay}

Kirby's disc diffusion assay was used to analyze the antimicrobial activity of ZnO NPs against $K$. pneumoniae and $E$. coli. A single colony of tested strain was grown overnight in nutrient broth medium on rotatory shaker at $(200 \mathrm{rpm})$ at $37^{\circ} \mathrm{C}$. The freshly prepared culture, $700 \mu \mathrm{l}$ of water and $200 \mu$ l of culture was taken through a micropipette and dissolved. This diluted culture was swabbed on solidified Muller Hinton agar plates. Sterile filter paper disks of Whatmann filter, $5 \mathrm{~mm}$ in diameter were used for disc diffusion assay. These blank discs impregnated with $(0.2,0.4,0.6,0.8$ and 1$) \mathrm{mg} / \mathrm{ml}$ concentrations of $\mathrm{ZnO}$ NPs were diffused. Standard discs of Imipenem (IPM) $(10 \mu \mathrm{g} / \mathrm{disc})$ and Ciprofloxacin (CIP) $(5 \mu \mathrm{g})$ were used as a positive while a blank disc (impregnated with water) was used as a negative control, respectively.

\section{Determination of minimum inhibitory concentration}

MIC is lowest concentration that prevents the visible growth of bacteria. Standard agar dilution method was used for estimation of MIC. The optical density (O.D) of bacterial suspension was maintained at $0.8-1$. Bacterial suspension having $10^{5}$ colony forming unit (CFU) $\mathrm{ml}^{-1}$ was added to each Muller Hinton agar plate containing different concentration of ZnO NPs and the growth of the bacteria was evaluated after $24 \mathrm{hrs}$ incubation at $37^{\circ} \mathrm{C}$.

\section{Evaluation of synergistic antibacterial activity}

$\beta$-lactam antibiotics i.e. IPM and CIP were selected in the present study. Both these antibiotics were dipped in different concentrations of ZnO NPs. After discs were diffused, plates were kept in incubator at $37^{\circ} \mathrm{C}$ for $18-24$ hours. The zones of inhibition thus formed were measured in millimeters. The maximum values were recorded. All tests were performed in triplicates.

\section{Antioxidant activity and cytotoxicity of $\mathrm{ZnO}$ nanoparticles}

Free radical scavenging activity was evaluated using L- ascorbic acid as standard antioxidant. The radical scavenging activity was measured using stable radical, DPPH according to method described by Chan et al. [10] with some modified cations [15]. All readings were compared with standard ascorbic acid (55 \pm 0.001). Tests were carried out in triplicates.

Brine shrimp lethality assay was used to analyze the cytotoxicity of ZnO NPs by following the protocol of Bibi et al. [16].

\section{Results}

\section{Antibacterial activity of $\mathrm{ZnO}$ nanoparticles}

ZnO NPs were able to inhibit the bacterial growth at all given concentrations and creating the maximum zone of inhibition at $1 \mathrm{mg} / \mathrm{ml}$ concentration i.e. $27.2 \mathrm{~mm}$ in $K$. pneumoniae (\#1) and $13.2 \mathrm{~mm}$ in E. coli (\#1). The comparison between these two strains is shown in Figure $\mathbf{1}$ and 2. The minimum inhibitory zones formed at $0.2 \mathrm{mg} / \mathrm{ml}$ concentration in $K$. pneumoniae (\#1) and $E$. coli (\#1) strains were measured as $19 \mathrm{~mm}$ and $8 \mathrm{~mm}$ respectively, as shown in Table 1.

\section{Determination of minimum inhibitory concentration}

The MIC value of ZnO NPs that inhibit the growth of bacteria was evaluated to be $0.05 \mathrm{mg} / \mathrm{ml}$ for $K$. pneumoniae and $0.08 \mathrm{mg} / \mathrm{ml}$ for $E$. coli. 


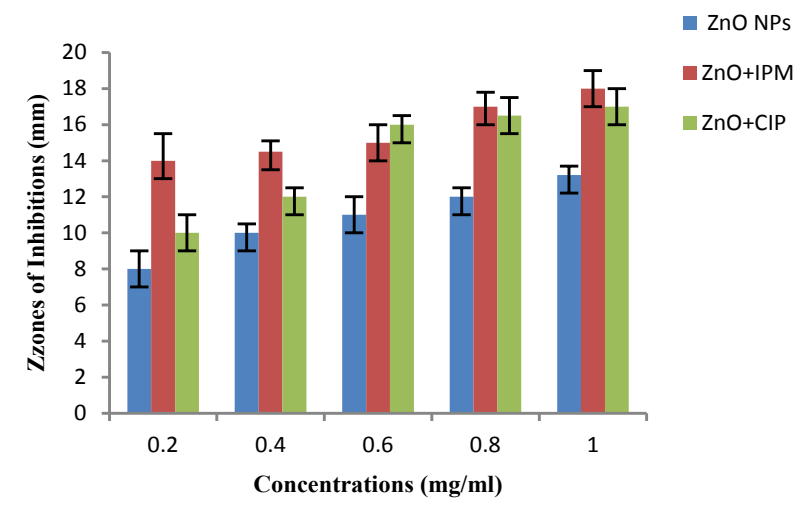

Figure 1 Zones of Inhibition formed at various concentrations of ZnO in E. Coli 1.

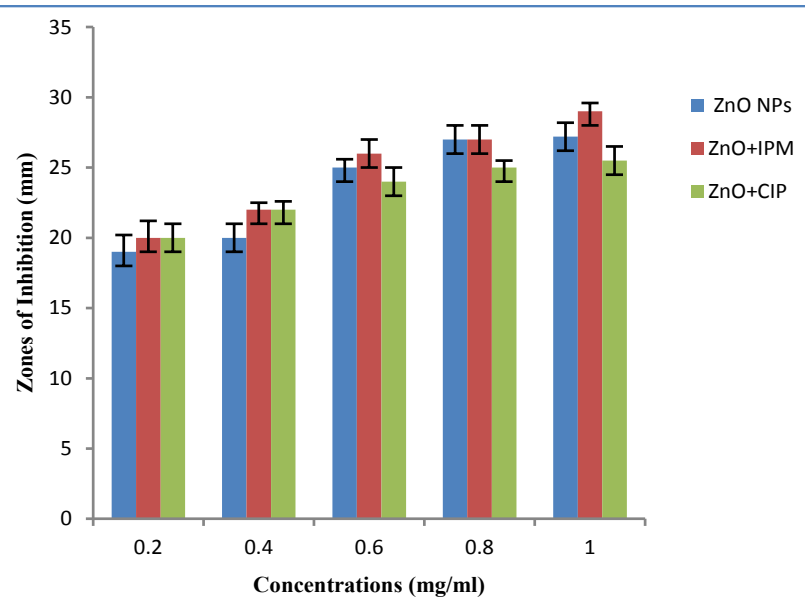

Figure 2 Zones of Inhibition formed at various concentration of $\mathrm{ZnO}$ in K. Pneumoniae 1.

Table 1 Zone of Inhibition in ( $\mathrm{mm}$ ) of free $\mathrm{ZnO}$ nanoparticles against tested bacterial strains.

\begin{tabular}{|c|c|c|c|c|c|c|}
\hline \multirow[b]{2}{*}{$\begin{array}{l}\text { Sr } \\
\text { No. }\end{array}$} & \multirow[b]{2}{*}{ Tested bacterium } & \multicolumn{5}{|c|}{ Zone of inhibition (mm) } \\
\hline & & $\begin{array}{c}0.2 \\
\mathrm{mg} / \mathrm{ml}\end{array}$ & $\begin{array}{c}0.4 \mathrm{mg} / \\
\mathrm{ml}\end{array}$ & $\begin{array}{c}0.6 \mathrm{mg} / \\
\mathrm{ml}\end{array}$ & $\begin{array}{c}0.8 \mathrm{mg} / \\
\mathrm{ml}\end{array}$ & $1 \mathrm{mg} / \mathrm{ml}$ \\
\hline \multirow{3}{*}{1.} & E. coli 1 & $8 \pm 1$ & $10 \pm 0.5$ & $11 \pm 1$ & $12 \pm 0.5$ & $13.2 \pm 0.5$ \\
\hline & E. coli 2 & $4 \pm 0.6$ & $5.5 \pm 2$ & $7 \pm 0.5$ & $10 \pm 2$ & $11 \pm 1$ \\
\hline & E. coli 3 & $\mathrm{R}$ & $\mathrm{R}$ & $\mathrm{R}$ & $\mathrm{R}$ & $\mathrm{R}$ \\
\hline \multirow{3}{*}{2.} & K. pneumoniae 1 & $19 \pm 1.2$ & $20 \pm 1$ & $25 \pm 0.6$ & $27 \pm 1$ & $27.2 \pm 1$ \\
\hline & K. pneumoniae 2 & $18 \pm 1.2$ & $19 \pm 1$ & $23 \pm 0.6$ & $24 \pm 1$ & $24.5 \pm 2$ \\
\hline & K. pneumoniae 3 & $7 \pm 1$ & $10 \pm 0.6$ & $15 \pm 0.6$ & $16 \pm 1$ & $16.3 \pm 2$ \\
\hline
\end{tabular}

\section{Evaluation of synergistic antibacterial activity}

Combined effect of ZnO NPs with $\beta$ lactam antibiotics i.e. CIP and IPM is shown in the Figures $\mathbf{3}$ and $\mathbf{4}$. The zones of inhibition formed are indicated in Table $\mathbf{2}$.

\section{Antioxidant and cytotoxicity of $\mathrm{ZnO}$}

The results showed the effective free radical percentage as $50 \%$ at $1 \mathrm{mg} / \mathrm{ml}$ concentration. Brine shrimp lethality test was used to determine the cytotoxicity of ZnO NPs. The average mortality percentage of dead larvae was evaluated to be $0 \%$, indicating the non-toxic effect of ZnO NPs.
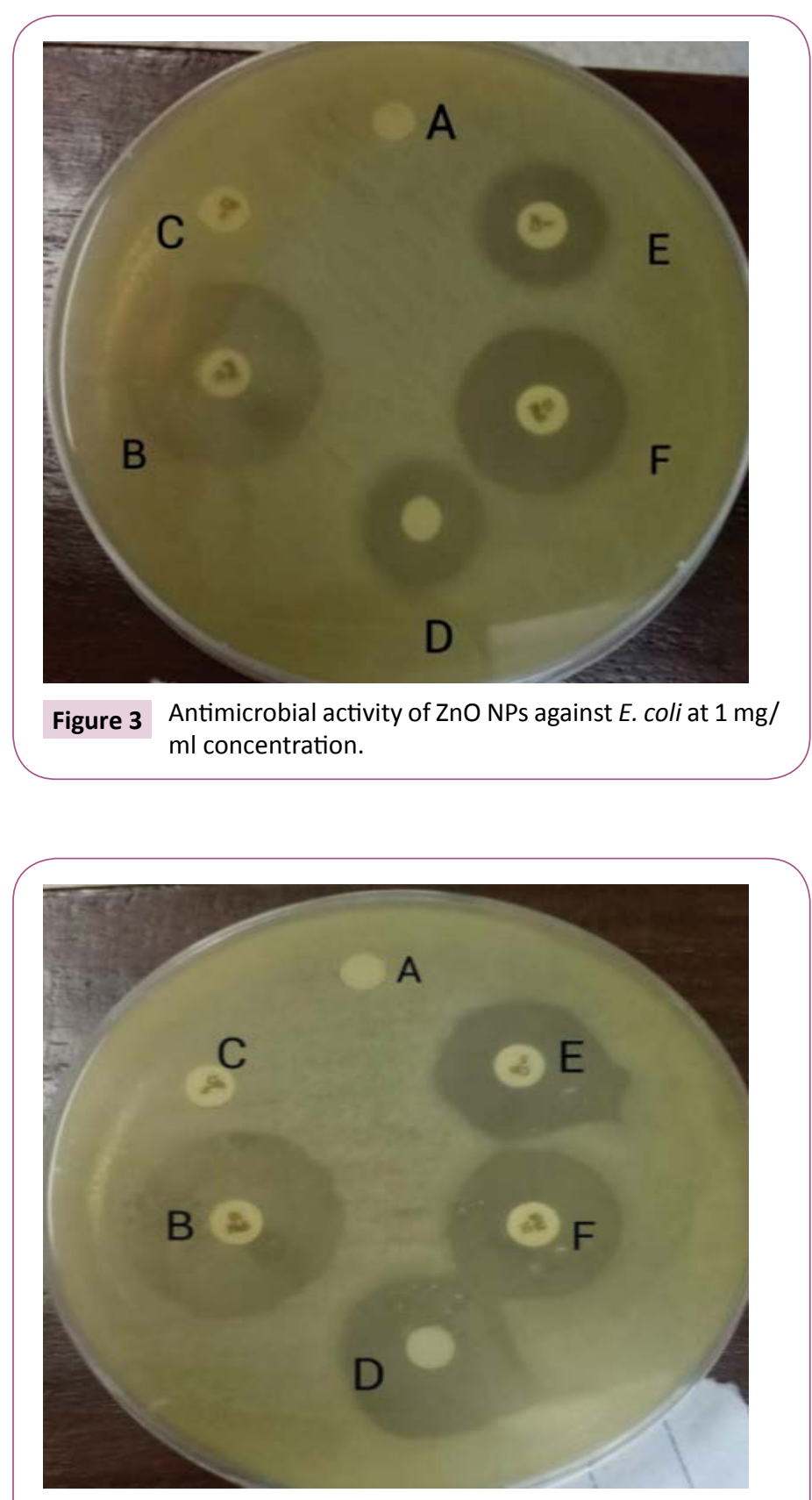

A Negative Control (distilled water); Positive Control; B (Imipenem) and C (Ciprofloxacin); D ZnO NPs; E ZnO + Ciprofloxacin; F ZnO + Imipenem.

Figure 4 Antimicrobial activity of ZnO NPs against $K$. pneumoniae at $1 \mathrm{mg} / \mathrm{ml}$ Concentration. 
Table 2 Zone of Inhibition in ( $\mathrm{mm}$ ) of ZnO Nanoparticles with Ciprofloxacin and Imipenem.

\begin{tabular}{|c|c|c|c|c|c|c|c|c|}
\hline \multirow{3}{*}{ Srno } & \multirow{3}{*}{ Treated bacterium } & \multirow{3}{*}{ Treatment } & \multicolumn{6}{|c|}{ Zone of Inhibition (mm) } \\
\hline & & & \multirow{2}{*}{ Antibiotics (alone) } & \multicolumn{5}{|c|}{ Antibiotic+ NPs } \\
\hline & & & & $0.2 \mathrm{mg} / \mathrm{ml}$ & $0.4 \mathrm{mg} / \mathrm{ml}$ & $0.6 \mathrm{mg} / \mathrm{ml}$ & $0.8 \mathrm{mg} / \mathrm{ml}$ & $1 \mathrm{mg} / \mathrm{ml}$ \\
\hline \multirow{6}{*}{1.} & \multirow{2}{*}{ E. coli 1} & Imipenem & 19 & $14 \pm 1.5$ & $14.5 \pm 0.6$ & $15 \pm 1$ & $17 \pm 0.8$ & $18 \pm 1$ \\
\hline & & Ciprofloxacin & $\mathrm{R}$ & $10 \pm 1$ & $12 \pm 0.5$ & $16 \pm 0.5$ & $16.5 \pm 1$ & $17 \pm 1$ \\
\hline & \multirow{2}{*}{ E. coli 2} & Imipenem & 20 & $13 \pm 0.5$ & $14 \pm 1$ & $15 \pm 0.6$ & $15.2 \pm 1$ & $16 \pm 1.5$ \\
\hline & & Ciprofloxacin & $\mathrm{R}$ & $2 \pm 1$ & $2.5 \pm 1$ & $3 \pm 1$ & $3.8 \pm 1$ & $4 \pm 0.6$ \\
\hline & \multirow{2}{*}{ E. coli 3} & Imipenem & $R$ & $\mathrm{R}$ & $\mathrm{R}$ & $\mathrm{R}$ & $\mathrm{R}$ & $\mathrm{R}$ \\
\hline & & Ciprofloxacin & $\mathrm{R}$ & $\mathrm{R}$ & $\mathrm{R}$ & $\mathrm{R}$ & $\mathrm{R}$ & $\mathrm{R}$ \\
\hline \multirow{6}{*}{2.} & \multirow{2}{*}{ K. pneumoniae 1} & Imipenem & 25 & $20 \pm 1.2$ & $22 \pm 0.5$ & $26 \pm 1$ & $27 \pm 1$ & $29 \pm 0.6$ \\
\hline & & Ciprofloxacin & $\mathrm{R}$ & $19.5 \pm 1$ & $23 \pm 0.6$ & $24 \pm 1$ & $25 \pm 0.5$ & $25.5 \pm 1$ \\
\hline & \multirow{2}{*}{ K. pneumoniae 2} & Imipenem & 29 & $21 \pm 1$ & $23 \pm 2$ & $24 \pm 1$ & $25 \pm 2$ & $26 \pm 0.5$ \\
\hline & & Ciprofloxacin & $\mathrm{R}$ & $10 \pm 2$ & $12 \pm 0.6$ & $14 \pm 2$ & $15 \pm 1$ & $17 \pm 1.5$ \\
\hline & \multirow{2}{*}{ K. pneumoniae 3} & Imipenem & 25 & $13 \pm 0.6$ & $15 \pm 2$ & $16 \pm 0.12$ & $17 \pm 1.2$ & $20 \pm 1.5$ \\
\hline & & Ciprofloxacin & $\mathrm{R}$ & $6 \pm 1.2$ & $6.3 \pm 0.1$ & $9 \pm 0.5$ & $11 \pm 1$ & $13 \pm 1.5$ \\
\hline
\end{tabular}

*All values are given as Mean \pm S.D

\section{Discussion}

Our findings revealed that antibacterial activity of $\mathrm{ZnO}$ NPs increases as the concentration of NPs increases and maximum inhibitory zone is obtained at $1 \mathrm{mg} / \mathrm{ml}$ concentration of $\mathrm{ZnO}$ NPs for both strains i.e. K. pneumoniae and E. coli. Thangham et al. [16] reported the same results where maximum zone of inhibition was formed at highest concentration of ZnO NPs [17]. The MIC values evaluated for $K$. pneumoniae and $E$. coli were 0.05 and $0.08 \mathrm{mg} / \mathrm{ml}$ respectively. Bhande et al. [18] in his study revealed the same results where MIC values for both $E$. coli and K. pneumoniae were recorded as $0.08 \mathrm{mg} / \mathrm{ml}$ and $0.06 \mathrm{mg} / \mathrm{ml}$ [18]. All strains were resistant towards CIP but the combined effect of CIP with ZnO NPs showed greater microbial inhibition. The highest zone of inhibition formed by combined effect of CIP with ZnO NPs in strain K. pneumoniae (\#1) was $25.5 \mathrm{~mm}$ which is greater than inhibitory zone of $E$. coli (\#1) i.e. $17 \mathrm{~mm}$. A remarkable increase in inhibition zone of $E$. coli (\#1) was observed where the zone of inhibition formed by the combined effect of ZnO NPs and CIP was $17 \mathrm{~mm}$, even more than the zone of inhibition of $\mathrm{ZnO}$ NPs alone i.e. $13.2 \mathrm{~mm}$. Iram et al. [15] investigated the effect of ZnO NPs with different antibiotics against Vancomycin resistant Enterococci and observed that combination of ZnO-CIP showed greater microbial inhibition than the ZnO NPs and CIP alone [19]. The combined effect of ZnO NPs with IPM showed significant decrease in efficiency of antimicrobial behavior of IPM. Similar results were obtained when Nazari et al. [19] analyzed the effect of gold nanoparticles (Au NPs) in combination with fourteen different $\beta$-lactam antibiotics against $E$. coli, Pseudomonas aeruginosa and Staphylococcus aureus. The results showed that Au NPs did not enhance the antibacterial effect of antibiotics at

\section{References}

1 Cohen ML (2000) Changing patterns of infectious disease. Nature 406: 762-767. tested concentration [20]. The enhanced antimicrobial behavior of IPM with ZnO NPs was observed in $K$. pneumoniae (\#1). At the maximum concentration of $1 \mathrm{mg} / \mathrm{ml}$, inhibitory zone formed by the combined effect was of $29 \mathrm{~mm}$ that is greater than the inhibitory zone of IPM alone i.e. $27 \mathrm{~mm}$. A similar study by Iram et al. [19] tends to support our results, where ZnO NPs showed greater antimicrobial activity with IPM [19]. One of the bacterial isolate $E$. coli (\#3) developed resistance against $\mathrm{ZnO}$ NPs and its combined effect with antibiotics. Joshi et al. [11] reported the same result where $E$. coli developed resistance against Silver nanoparticles (Ag NPs) due to the overproduction of extracellular polymeric substances (EPS), colanic acid that protected the bacteria against Ag-NPs [21]. Results revealed that the antioxidant activity increases by increasing the concentration of nanoparticles. Azizi et al. [20] reported the same result where the scavenging of DPPH radicals was found to be increasing as the concentration of ZnO NPs increases [22]. The cytotoxicity of ZnO NPs against brine shrimp larvae indicated the non-toxic effect of ZnO NPs. A similar study by Ates et al. [19] revealed that ZnO NPs suspension possesses less toxicity [23].

\section{Conclusion}

The present study would suggest the possible utilization of $\mathrm{ZnO}$ NPs incorporated antibiotics to prevent the fatal diseases caused by pathogenic bacteria. Taken together, this compound as a highly safe and non toxic may be considered for combination therapies against pathogenic bacteria due to its potential antimicrobial effect with important antibiotics. Further study will helpful to formulate nano-drug conjugate as an anti-microbial agent in a large scale level through standardized regulatory conditions. 
3 Bradford PA (2001) Extended-spectrum $\beta$-lactamases in the 21st century: characterization, epidemiology, and detection of this important resistance threat. Clinical microbiology reviews 14: 933-951.

4 Jones N, Ray B, Ranjit KT, Manna AC (2008) Antibacterial activity of $\mathrm{ZnO}$ nanoparticle suspensions on a broad spectrum of microorganisms. FEMS microbiology letters 279: 71-76.

5 Jacoby GA, Archer GL (1991) New mechanisms of bacterial resistance to antimicrobial agents. New England Journal of Medicine 324: 601-612.

6 Taylor PW, Stapleton PD, Luzio JP (2002) New ways to treat bacterial infections. Drug discovery today 7: 1086-1091.

7 Ahmad A, Mukherjee P, Senapati S, Mandal D, Khan M, et al. (2003) Extracellular biosynthesis of silver nanoparticles using the fungus Fusarium oxysporum. Colloids and surfaces B: Biointerfaces 28: 313-318.

8 Sastry M, Ahmad Islam NI, Kumar R (2003) Current Science 85: 162.

9 Lara HH, Ayala-Núñez NV, Turrent LDCI, Padilla CR (2010) Bactericidal effect of silver nanoparticles against multidrug-resistant bacteria. World Journal of Microbiology and Biotechnology 26: 615-621.

10 Matei A, Cernica I, Cadar O, Roman C, Schiopu V (2008) Synthesis and characterization of $\mathrm{ZnO}$-polymer nanocomposites. International Journal of Material Forming 1: 767-770.

11 Ghule K, Ghule, AV, Chen BJ, Ling YC (2006) Preparation and characterization of $\mathrm{ZnO}$ nanoparticles coated paper and its antibacterial activity study. Green Chemistry 8: 1034-1041.

12 Sawai J (2003) Quantitative evaluation of antibacterial activities of metallic oxide powders ( $\mathrm{ZnO}, \mathrm{MgO}$ and $\mathrm{CaO}$ ) by conductimetric assay. Journal of microbiological methods 54: 177-182.

13 Raghupathi KR, Koodali RT, Manna AC (2011) Size-dependent bacterial growth inhibition and mechanism of antibacterial activity of Zinc oxide nanoparticles. Langmuir 27: 4020-4028.

14 Li M, Zhu L, Lin D (2011) Toxicity of ZnO nanoparticles to Escherichia coli: mechanism and the influence of medium components. Environmental science \& technology 45: 1977-1983.
15 Chan EWC, Lim YY, Chew YL (2007) Antioxidant activity of Camellia sinensis leaves and tea from a lowland plantation in Malaysia. Food chemistry 102: 1214-1222.

16 Bibi G, Ullah N, Mannan A, Mirza B (2011) Antitumor, cytotoxic and antioxidant potential of Aster thomsonii extracts. African Journal of Pharmacy and Pharmacology 5: 252-258.

17 Thangam A, Pritam S, Ramlakshmi S (2014) Effect of ZnO nanoparticles against strains of Escherichia coli. Asian Journal of Pharmaceutical and clinical research 7: 202-206.

18 Bhande RM, Khobragade CN, Mane RS, Bhande S (2013) Enhanced synergism of antibiotics with zinc oxide nanoparticles against extended spectrum $\beta$-lactamase producers implicated in urinary tract infections. Journal of nanoparticle research 15: 1413.

19 Iram S, Khan JA, Aman N, Nadhman A, Zulfiqar Z, et al. (2016) Enhancing the Anti-Enterococci Activity of Different Antibiotics by Combining with Metal Oxide Nanoparticles. Jundishapur journal of microbiology 9.

20 Nazari ZE, Banoee M, Sepahi AA, Rafii F, Shahverdi AR (2012) The combination effects of trivalent gold ions and gold nanoparticles with different antibiotics against resistant Pseudomonas aeruginosa. Gold Bulletin 45: 53-59.

21 Joshi N, Ngwenya BT, French CE (2012) Enhanced resistance to nanoparticle toxicity is conferred by overproduction of extracellular polymeric substances. Journal of hazardous materials 241 : 363-370.

22 Azizi S, Mohamad R, Mahdavi Shahri M (2017) Green microwaveassisted combustion synthesis of zinc oxide nanoparticles with Citrullus colocynthis (L.) Schrad: Characterization and biomedical applications. Molecules 22: 301.

23 Ates M, Daniels J, Arslan Z, Farah IO, Rivera HF (2013) Comparative evaluation of impact of $\mathrm{Zn}$ and $\mathrm{ZnO}$ nanoparticles on brine shrimp (Artemia salina) larvae: effects of particle size and solubility on toxicity. Environmental Science: Processes \& Impacts 15: 225-233. 